\title{
Engineering Engineering Education \\ A Conceptual Framework for Supporting Faculty in Adopting \\ Collaborative Learning
}

Session 3531

\author{
Brian Hoyt, Michael Prince, Steve Shooter, Michael Hanyak, , \\ E.J. Mastascusa, William Snyder, T. Michael Toole, Mathew Higgins, \\ Daniel C. Hyde, Marie Wagner, Margot Vigeant
}

\author{
Bucknell University
}

\begin{abstract}
Over the last three years, nearly a quarter of Bucknell's engineering faculty have participated in Project Catalyst, a NSF funded project to promote systemic change in engineering education by integrating instructional design techniques, transforming the classroom into a cooperative learning environment, and incorporating the use of information technology in the teaching/learning process. One of the major outcomes of that work is a conceptual framework for assisting faculty in transitioning from more traditional instructional modes to more collaborative modes of instruction. Drawing heavily on a typical engineering process, this framework maps concepts readily understood in the engineering design world to the development of instructional experiences. This paper outlines that framework and discusses our efforts to export this framework to faculty beyond Bucknell through a pair of national workshops conducted last summer. Included is our assessment of the effectiveness of this effort, both in terms of impact on Bucknell faculty and on the workshop participants.
\end{abstract}

\section{Introduction}

Bucknell's College of Engineering is implementing Project Catalyst, a three-year effort to develop a general-purpose model for the nationally recognized need of systemic engineering education reform. This NSF-sponsored project focuses on the four-year undergraduate curricula in all five engineering disciplines (chemical, civil and environmental, electrical, and mechanical and computer science) at Bucknell University. Specifically, Project Catalyst provides an environment in which to promote change and encourage faculty members, students, and administrators to re-envision their roles in the engineering learning process.

To understand the motivation for this project, recall your undergraduate classroom experience. If you're a typical engineer, you probably had one or more of the following experiences:

- The professor lectured for 50 minutes, and you copied into your notebook what was written on the board. 
- The professor assumed all students have similar learning styles.

- The professor focussed on the content rather than on how you should approach learning the material.

- Teamwork was generally not encouraged. If anything, engineering was viewed as a solitary profession, except for laboratory work.

- A clear presumption existed that the goal of the professor was to transfer the material to you.

Although much progress has been made, this model still survives today in far too many engineering classrooms [1]. This style is characterized by subject-based, teacher-directed learning. The success of the course is measured by how much material is covered-often specified by the number of book chapters that are covered. Success is not measured by how well students learn the material, or by the depth of their learning - for example, as measured by where they are on Bloom's cognitive taxonomy [2]. This approach has been the mainstay in engineering education, producing graduates with strong technical capabilities but with limited teamwork, written and oral communication skills, creativity, imagination, and lifelong learning skills [3].

Project Catalyst [4] intended to address the systemic change needed in the engineering classroom by having faculty collaborate in teams to re-envision their roles in the learning process with the ultimate goals of:

- learning and integrating instructional design techniques into engineering courses,

- transforming the classroom into a cooperative learning environment, and

- efficiently and effectively incorporating the use of information technology.

Early in the first year of the project's implementation, based on our exploration of the literature in the field and realizing the need for having specific structures to adopt, the team began to focus its efforts on applying Bloom's taxonomy, Kolb's Learning Style Inventory, and cooperative learning as the primary mechanisms for accomplishing the first two goals. The use of course management software became the primary tool for accomplishing the third goal.

Several interesting lessons were learned from our initial trials at implementing cooperative learning $[5,6,7]$. First, working in teams does not come easily for faculty or students. It was found that faculty teams are harder to form than student teams but are essential because individual faculty efforts are not capable of producing systemic change. From the student point of view, the team structure seemed to prevent the weaker students from falling too far behind their peers. Second, effective teaming requires time and wellstructured exercises in team development. Third, overcoming resistance to teamwork is difficult and requires instruction in teamwork and problem solving skills in order to gain the maximum benefit from cooperative learning. Fourth, more often than not, we found ourselves being driven to problem base learning because real problems provided a realistic, motivating context for the teams used in cooperative learning. Finally, to develop the desired levels of proficiency in the problem solving and team skills of students, it is necessary to have consistent repeated teaming exercises throughout the curriculum. 
Over the course of the following two years, in addition to engaging nearly a quarter of the university's engineering faculty in the project and conducting over 20 course redesign efforts, the Project Catalyst Team has developed a series of tools and conceptual frameworks to assist faculty in making the transition from more traditional instructional practices to cooperative and problem-based learning. These frameworks range from a model for understanding the differences in when and where instructional activities take place between traditional and collaborative learning, to a series of Supplementary Skills Modules (SSM). The SSMs support student skill development in the areas of problem solving, teamwork, and information technology to a staged curriculum model for integrating problem solving and teaming into the curriculum [6,7].

With these tools in place, the team then turned its attention to developing a conceptual framework that could be used by faculty as they worked through the process of transitioning a course from a more traditional instructional experience to one centered on cooperative and problem-based learning. The framework that emerged from the team's discussions has been dubbed Engineering Engineering Education.

\section{The Engineering Engineering Education Conceptual Framework}

In conceptualizing possible frameworks for the course design process, the Catalyst team drew heavily on their shared beliefs that 1) engineering faculty should use whatever scientific knowledge exists about teaching and learning and 2) they should use that knowledge in a systematic way. Furthermore, as the Catalyst team outlined the process they had been following in their respective course redesign efforts, it became clear that these processes mapped nicely into a design methodology (see Table 1). Hence, Project Catalyst has adopted an engineering design/course design analogy as its primary vehicle for communicating with faculty about the instructional practices it believes will contribute to the desired systemic change.

\begin{tabular}{|cc|}
\hline Engineering Design Process & Course Design Process \\
\hline Needs Analysis & Define Course Goals \\
Problem Definition/Get Specs & Develop Course Outcomes \\
Devise Solutions & Select Instructional Practices \\
Fill In Details & Develop Instructional Materials \\
Predict Performance & Test Instructional Materials \\
Build & Implement Instructional Activities \\
Measure Performance \& Check Vs Specs & Assess Outcomes \\
\hline
\end{tabular}

Table 1- Engineering Design \& Course Design Analogy

The strength of this framework lies in the fact that the course design process is analogous to the engineering design process with which engineering faculty are familiar. Consequently, we are able to talk about the specifications being analogous to course outcomes and measuring performance being analogous to assessing outcome achievement. Also, choosing between the various active learning techniques is analogous to selecting between design techniques or solution strategies in a given discipline. It not only provides a methodology for faculty to follow in course redesign efforts, but, it also 
provides a platform for organizing a series of workshops to assist faculty in conducting course redesign efforts.

\section{The Components of the Model}

Each stage in the model has associated with it several pieces of pedagogical theory that need to be understood and applied by faculty members engaged in the course design effort in that particular stage of the course design project. Brief summaries of the "technical" skills that Project Catalyst has associated with each of the stages in our course design process are provided below.

Define Course Goals: At this stage in the process we suggest to faculty that they think about the instructional need that the course is addressing much as they would identify the societal need that a design is intended to address. We also ask faculty to consider the areas of EC2000 that they expect their course to address and how does this course fit into the sequence of course in their curriculum. We coach faculty to state goals broadly and to check that the goals developed for a course focus on both the "content" of the course and non-content areas such problem solving, team work and life long learning.

Develop Course Objectives: This stage focuses on translating the goals into a series of outcomes based on Bloom's taxonomy - a process that is very similar to translating a need into a defined problem or a set of specifications. In addition, faculty are coached to make outcomes specific, attainable, measurable, linked to a performance time frame, and stated with the conditions of performance. To aid faculty in developing course objectives, we have drawn on the work of the Engineering Education Assessment Methodologies and Curriculum Innovation Project [8] which has developed a conceptual framework for writing course objectives based on Bloom's taxonomy as well as compiled a rich set of action verbs applicable to each level [9] that we have found faculty can readily relate to and associate easily with their current instructions practices.

Select Instructional Practices: The focus in this stage of the model is on selecting from a series of best instructional practices relating to the use of learning style theory and from a variety of active, cooperative, collaborative and problem-based learning activities. Faculty are encouraged to first pick the active learning category (active, collaborative, cooperative, or problem-based - with special emphasis on last two types) that they are currently comfortable implementing and, within that category, instructional activities which are appropriate for the course outcomes students are expected to achieve. For the purposes of this model we define active learning as any learning activity that engages students in doing something other than listening to lectures and taking notes. These activities may involve students interacting with each other, writing, reading or reflecting individually. As an initial active learning implementation step, faculty are encouraged to break up their lectures with an active learning activity every 20 minutes. The model continues by introducing collaborative learning as a subset of active learning in which the focus of the learning activities begins to shift from the instructor's presentations of the course material to the student's exploration of it. We tell faculty that collaborative learning activities are generally typified by "group" work where students work together 
but are usually rewarded and evaluated as individuals not as group members. The model then introduces them to a structured form of collaborative learning--cooperative learning whose implementation is characterized by the presence of five elements: positive interdependence, individual accountability, face-to-face interaction, appropriate use of interpersonal skills and the regular self-assessment of group functioning [10]. Lastly, the model introduces problem-based learning which we have defined to be the use of a problem situation to drive the learning activities where students working in teams figure out what they need to know, determine how to acquire the needed knowledge, apply the knowledge to solve the problem and assess the solution and the process. The relationship between these instructional practices is depicted in Figure 1. In addition to showing the subset relationships of these instructional practices, we also use this depiction to develop the case for faculty that the closer their instructional activities are to the center of the diagram the more likely their students are to be engaged with the material.
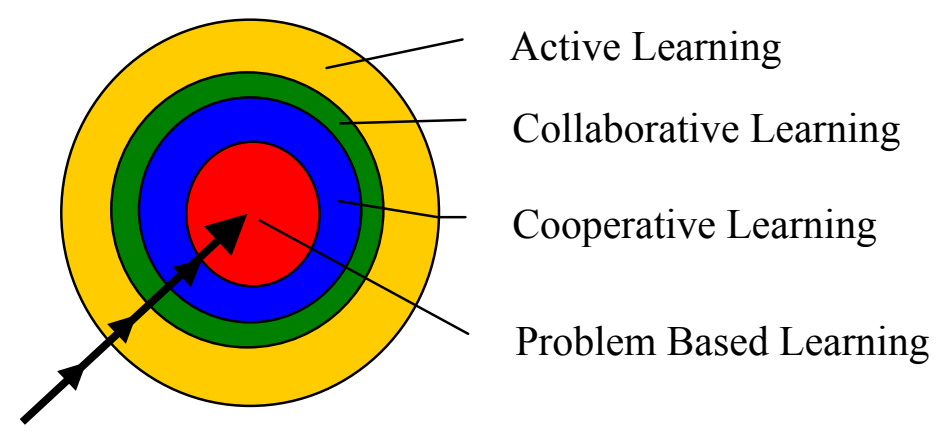

Increasing Engagement

Figure 1-Active Learning Engagement Hierarchy

Develop Instructional Materials: In this stage of the model faculty actually develop their instructional modules. Considerable coaching is provided on aspects of implementing team-based activities such as how to form teams, how to assess team performance, and how to deal with dysfunctional teams. Faculty are also given considerable guidance in how to prepare students for the problem solving challenges they will encounter during the course of the learning activity.

Test Instructional Materials: Here we encourage faculty to test out their modules either with other faculty or on small groups of students. The value of starting small and prototyping activities is also emphasized here. The Catalyst team has found that having faculty present their instructional plans and receive feedback from their colleagues is an invaluable part of the course design process.

Implement Instructional Activities: Here we stress with faculty the value of not implementing collaborative or problem based learning alone. The Catalyst team has 
found great solace in regular Whine and Cheese gatherings where we get together to share our successes, and our struggles, and receive encouragement and coaching from each other. The value of getting frequent feedback from students to gauge how they are coping with the change in the instructional practices is also stressed.

Assess Outcomes: Here classroom assessment techniques and options are discussed with faculty. Assessing at the highest possible point on Bloom's taxonomy is stressed as well as the need for the level of assessments to be consistent with the written course outcomes Application of the Engineering Engineering Education Framework

During the summer of 2003 the Project Catalyst team utilized this framework as the basis for delivering two one-week workshops for faculty from across the country. From a pool of over 400 applicants we selected 48 faculty participants. Because the faculty teamwork aspect is such a valuable part of the Catalyst experience, in as many cases as we could, we invited multiple participants from an institution with the hopes that they would better be able to support each other when they returned to their institution.

This workshop was designed to introduce participants to principles of instructional design with a special emphasis on hands-on, practical development of instructional materials that can be used in the classroom. Participants took part in collaborative activities to help them identify their specific learning objectives and develop an overview of educational "best practices" that can be used to achieve those outcomes. The workshop also provided an opportunity for faculty to develop appropriate assessment tools to measure the effectiveness of the learning materials. The participants worked actively to redesign courses and create instructional materials with a special emphasis on active, cooperative and problem-based learning. The workshop also contained experiences aimed at increasing the participants confidence in their ability to develop the teamwork and problem solving skills of their students, to structure courses to accommodate active learning activities without the loss of course content, to use instructional technology effectively, and to develop a support structure to continue educational innovations beyond the workshop. Throughout this experience the faculty coaches focused on not telling faculty how they must teach, but on providing an overview of different teaching methods, their rationale and then letting faculty choose their own comfort level.

The participants spent a week at Bucknell engaged in a series of collaborative and problem-based learning experiences which resulted in their applying our systematic course design process to a portion of a course they would be teaching in the upcoming academic year and equipping them to complete the design once they returned to their campuses [6]. At the end of each session, the participants made a presentation to their peers about their redesign efforts during the week and their plans for the upcoming academic year. In addition, the Catalyst team developed for use by the participants a Practical Guide to Teamwork and the Project Catalyst Problem-based Learning Handbook. These resources as well as other resources that have been assembled by the Project Catalyst team can be found at the project's website (www.departments.bucknell.edu/projectcatalyst) 


\begin{tabular}{|c|c|c|c|c|c|c|c|c|c|c|}
\hline Question & 7 & 6 & 5 & 4 & 3 & 2 & 1 & $\begin{array}{c}\text { Total \# } \\
\text { Responses }\end{array}$ & $\begin{array}{c}\text { Average } \\
\text { (High 7.0) }\end{array}$ & $\begin{array}{l}\text { Standard } \\
\text { Deviation } \\
\end{array}$ \\
\hline $\begin{array}{l}\text { Please summarize your } \\
\text { overall experience at the } \\
\text { workshop. }\end{array}$ & Very Positive & & & Neutral & & & $\begin{array}{l}\text { Very } \\
\text { Poor }\end{array}$ & & & \\
\hline Week 1 & 18 & 5 & 0 & 0 & 0 & 0 & 0 & 23 & 6.78 & 0.42 \\
\hline Week 2 & 23 & 0 & 0 & 0 & 0 & 0 & 0 & 23 & 7.00 & 0.00 \\
\hline $\begin{array}{l}\text { To what extent did the } \\
\text { workshop provide you } \\
\text { with practical concepts } \\
\text { and tools that will } \\
\text { improve your teaching? }\end{array}$ & $\begin{array}{c}\text { Extremely } \\
\text { Helpful }\end{array}$ & & & Neutral & & & $\begin{array}{l}\text { Not } \\
\text { at } \\
\text { All } \\
\end{array}$ & & & \\
\hline Week 1 & 20 & 2 & 1 & 0 & 0 & 0 & 0 & 23 & 6.83 & 0.49 \\
\hline Week 2 & 15 & 7 & 1 & 0 & 0 & 0 & 0 & 23 & 6.61 & 0.58 \\
\hline $\begin{array}{l}\text { Would you recommend } \\
\text { this workshop to other } \\
\text { colleagues at your } \\
\text { institution? }\end{array}$ & \begin{tabular}{c|} 
Strongly \\
Recommended
\end{tabular} & & & Neutral & & & $\begin{array}{c}\text { Not } \\
\text { at } \\
\text { All } \\
\end{array}$ & & & \\
\hline Week 1 & \begin{tabular}{|l|}
21 \\
\end{tabular} & 1 & 1 & 0 & 0 & 0 & 0 & 23 & 6.87 & 0.46 \\
\hline Week 2 & 21 & 2 & 0 & 0 & 0 & 0 & 0 & 23 & 6.91 & 0.29 \\
\hline $\begin{array}{l}\text { How effective were the } \\
\text { workshop coaches? }\end{array}$ & $\begin{array}{l}\text { Extremely } \\
\text { Helpful }\end{array}$ & & & Neutral & & & $\begin{array}{l}\text { Not } \\
\text { at } \\
\text { All }\end{array}$ & & & \\
\hline Week 1 & 17 & 5 & 0 & 1 & 0 & 0 & 0 & 23 & 6.65 & 0.71 \\
\hline Week 2 & 15 & 6 & 0 & 2 & 0 & 0 & 0 & 23 & 6.48 & 0.90 \\
\hline
\end{tabular}

Table 2-Summary of Feedback Provided by Workshop Participants

\section{Impact of Project Catalyst on Faculty Participants}

Based on the feedback we received from the workshop some of which is summarized in Table 2 below, we have been able to draw some conclusions about our framework for communicating the course design process. First and foremost, the models we have developed for communicating the Engineering Engineering Education change model resonate with faculty. Even the most skeptical of the faculty participants were believers by the conclusion of the week. Second, while we knew the right thing to do was to have the participants actively participate in the learning we wanted to take place, the effect of the reinforcing effect of walking the talk was a significant contributor to the success of the workshops. On this subject, one of the participants commented: "The workshop provides extremely valuable and useful experience and materials for improving teaching in the engineering education. The teamwork and interactions between coaches and participants are great. The Catalyst team is a great example for us to see how well the teamwork works. This is the best workshop that I have ever attended, we have ideas that what we could do in teaching after this workshop." Third, although the effort we spent early in the project forming the core group of Bucknell faculty into a team was difficult and at times even painful, the value of those team-based relationships were instrumental in making the workshop a success. In fact, one of the shortcomings of our model currently is the difficulty of transferring the faculty teaming portion of our model to other institutions. Finally, while we have been able to involve nearly a quarter of the Bucknell 
engineering faculty in this project in a significant way, we seem to have reached a glass ceiling of participation on our campus.

\section{Conclusions}

The Project Catalyst team has developed a conceptual framework for communicating a systematic course design model that relies on the body of literature that exists about teaching and learning. The framework is based on a series of analogs to a typical engineering design process. This framework has been used by Project Catalyst team members both in the design of instructional materials for their own courses and in a pair of workshops given to faculty from across the country last summer. Preliminary assessment efforts indicate that the framework is an effective tool for both performing course design and communicating about strategies for course design. The workshop materials which have come out of the effort to develop this framework will be enhanced, and the workshops will be given again during the summer of 2003.

\section{Acknowledgements}

We wish to acknowlege the National Science Foundation for funding Project Catalyst (NSF 9972758). We also thank Bucknell University which provided both financial and moral support for this project.

\section{REFERENCES}

[1] Woods, D. R. "Three Trends in Teaching and Learning." Chemical Engineering Education, Vol. 32, No. 4, 1998, pp. $296-301$.

[2] Bloom, Benjamin S. (ed.), Taxonomy of Educational Objectives. Handbook I: Cognitive Domain, David McKay Co., 1956.

[3] Felder, R. M., G. N. Felder, and E. J. Dietz, "A Longitudinal Study of Engineering Student Performance and Retention. V. Comparisons with Traditionally-taught Students”, Journal of Engineering Education, Vol. 87, No. 4, 1998, pp. 469-480.

[4] Hanyak, M. E., et al., "Combining Faculty Teamwork, Applied Learning Theory, and Information Technology: A Catalyst for Systemic Engineering Education Reform," National Science Foundation Four Year Grant (\#99-72758), College of Engineering, Bucknell University, Lewisburg, PA, October, 1999.

[5] Prince, M. J., M. F. Aburdene, B. S. Hoyt, D. C. Hyde, E.J. Mastascusa, et al., "Project Catalyst: Successes and Frustrations of Introducing Systemic Change to Engineering Education", Proceedings of the 2001 ASEE Annual Conference, Albuquerque, NM, June 24-27, 2001

[6] Prince, M., , M. Hanyak, B. Hoyt, D. C. Hyde, E.J. Mastascusa, et. al., "A Conceptual Framework for Progressively Developing Students' Team and Problem Solving Skills Across the Curriculum", Proceedings of the 2002 American Society for Engineering Education Annual Conference \& Exposition, Copyright 2002, American Society for Engineering Education.

[7] Prince, M., B. Hoyt, "Helping Students Make the Transition from Novice to Expert Problem Solvers", Proceedings of the $32^{\text {nd }}$ Frontiers in Education Conference, Copyright 2002, IEEE.

[8] http://www.engr.pitt.edu/ ec2000/

[9] Besterfield-Sacre, Mary E, et al., "Defining the Outcomes: A Framework for EC 2000," IEEE Transactions on Engineering Education, Vol. 43, No. 2, May, 2000. Also, available at www.engrng.pitt.edu/ ec2000.

[10] Johnson, David W., Roger T. Johnson, and Karl A. Smith, Active Learning: Cooperation in the College Classroom, Interaction Book Company, Edina, MN, 1998. 